\title{
Feto-Maternal Out-Come Of Advanced Maternal Age-A Clinical Study In BSMMU.
}

\author{
Dr. Ummul Nusrat Zahan, Dr. Ferdous Ara Suchi, Dr. Sufia Begum Shampi; Dr. \\ G.W.M.Zahidul Hasan \\ Assistant Professor Dept Of Obstetrics And Gynaecology Delta Medical College \& Hospital, Dhaka, \\ Bangladesh. \\ Associate Professor Dept Of Obstetrics \& Gynaecology Delta Medical College \& Hospital, Dhaka, Bangladesh. \\ Assistant Professor Dept Of Obstetrics And Gynaecology Delta Medical College \& Hospital, Dhaka, \\ Bangladesh. \\ Specialist in Family Medicine Armed Forces Hospital, Najran, Kingdom of Saudi Arabia.
}

\begin{abstract}
Day by day there is a definite increase in the number of woman bearing children in their older age. So, elder maternal age has become an important topic in the world wide. But yet it has not received adequate attention in our country. This study has done with an objective to find out problems associated with pregnancy and perinatal outcome in woman 35 years of age and above. It is a comparative study. This study was done in BSMMU from August 2008 to January 2009. A total 1130 obstetric patient were admitted during this study period. From this admitted patient consecutive 35 patients were selected for this study, whose ages were above 35 years. At the same time 35 patients were selected as a control, whose age was below 35 years.

Among 35 elderly patients caesarian section was significantly high both in elderly patients (Group A) $88.5 \%$ \& control group (Group B) 63\%, followed by vaginal delivery (11.5\% Vs 37\%).

Pregnancy complications were found significantly high in A group (57\%) compared to B group(20\%). Most common complications observed in group A were APH $14.2 \%$, preeclampsia $11.4 \%$, malpresentation $11.4 \%$, obstructed labour $8.5 \%$ oigohydramnions $5.7 \%$.

Post delivery maternal complications were more in A group (40\%) compared to B group (23\%). Failure of lactation was found more in A group $(11 \%)$ compared to B group $(5.7 \%)$, PPH was found $8.5 \%$ in $A$ group and $5.8 \%$ in B group, wound infection $5.8 \%$ in A group and $2.8 \%$ in B group, emergency peripartum hysterectomy $5.7 \%$ in $A$ group and $2.8 \%$ in $B$ group. The rate of alive baby in group $A$ was $86 \%$ and group $B$ was $94 \%$, still born rate in Group $A$ and Group $B$ was respectively $8.5 \%$ \& $2.8 \%$ and early neonatal death was respectively $5.7 \% \& 2.8 \%$.

Such clinical observation has led to the belief that pregnancy in older woman are at special risk. It is expected that result of the study will make attention of the national policy maker. Therefore there may be significant improvement of taking care of these patients. Also social awareness should be created about complication that may arise in the elderly pregnancy.
\end{abstract}

Key words: Advanced maternal age, Feto-maternal outcome, High risk pregnancy, Perinatal motility, and post delivery complication.

\section{Introduction:}

Advance maternal age usually defined as age 35 or more for the mother at the time of delivery of her baby ${ }^{1}$. The definition of advance maternal age varies from study to study with most of the earlier reports fixing the cutoff points at 35 years and more recent one around 40 years. ${ }^{2}$

In today's society, it has become more common place for woman to consider pregnancy at age 35 or older for a variety of reasons. One have pursued education, careers, or have married later in life than woman done decades ago. And some are simply choosing to have one more baby in their life time, even after one or two previous pregnancies. Infertility problems are more prevalent as a woman as a woman gets older, yet technology has helped many woman succeed in achieving a much desired pregnancy. Statistically, there are more pregnant woman over the age of 35 than in any other era. ${ }^{3}$

However in developing country like Bangladesh, pregnancy at advance age is mostly due to lack of knowledge and interest in family planning methods eagerness for a mail child and in small number of cases due to carrier choice or infertilities. ${ }^{4}$

A mother with advance age are higher risk of developing certain complications during pregnancy such as gestational diabetes, preeclampsia, placental abruption and placenta previa ${ }^{5}$ However age alone does not predict risk, but several lifestyle factors, such as family history, socioeconomics, and demographics have major impacts on the well-being of the mother and infant. ${ }^{5}$ 
Research shows that chance of having a low-birth weight baby or a premature delivery increase with age. Woman over age 35 are at increased risk of having a child with certain birth defects involving chromosomes. Down syndrome is the most common chromosomal birth defect. ${ }^{6}$

The increased risk of this problems is largely due to underlying medical problems more common in older woman. ${ }^{4}$ In our country ignorance, lack of adequate health care, delivery by traditional birth attendance and irregular antenatal care are mainly responsible for complication and poor outcome of these pregnancy ${ }^{6}$.

The aim of my study is to investigate the influence of maternal age on perinatal and obstetric outcome in woman aged 35 years or older. Hopefully this study will give a gross idea about perinatal outcome in woman aged 35 years or older.

\section{Aims and objectives of the study \\ General objective:}

- Is to find out the influence of advance maternal age on fetomaternal outcome.

Specific objective:

- To find out maternal complication associated with pregnancy in woman 35 years of age and above compared to those with age below 35 years.

- To get fetal outcome in advance maternal age.

- To find out the underlying cause of pregnancy at advanced maternal age.

\section{Materials and methods:}

Type of study: comparative case control study.

Place of study: Bangabandhu Sheikh Mujib Medical University (BSMMU) Hospital, Dhaka, Bangladesh.

Period of study: From August 2008-January2009.

Study population: pregnant woman of age 35 years or above as a case and pregnant woman of age below 35 years as a control group.

Sample size: Total 35 patients attending in the labour word and in patient department of obstetrics and Gynecology, BSMMU were enrolled in the study.

\section{Inclusion criteria for case:}

Pregnant woman of 35 years of age or above irrespective of parity.

- Pregnant woman gestational age in between 28 to 42 weeks who are admitted for labour management.

\section{Inclusion criteria for control:}

- Pregnant woman age below 35 years.

- Pregnant woman gestational age in between 28 to 42 weeks who are admitted for labour management.

Detail procedure: consecutive 35 patients whose age 35 years or above were selected for sampling after their admission in the hospital. Patients were informed about the purpose and procedure of the study and written consent was taken. After that detailed history was recorded and clinical examination was done. All laboratory investigations were seen. Patients were monitored in intranatal and post-natal period. Mode of delivery, any chronic medical disease or complication arises during pregnancy were recorded. Intensive care unit admission was also noted. New born babies were assessed immediately after birth. Resuscitation measures were noted. The mother and new born were assed daily during their stay in hospital. During this time their progress deterioration and interventions was recorded. Another 35 pregnant patients, age below 35 years were taken as a control, for comparative study. They were monitored in the same way. Pregnant woman of age 35 years or above shown as group A and pregnant woman of age below 35 years are shown as group B.

III. Results and observations:

Table-1: Pregnancy complication in relation to maternal age

\begin{tabular}{|lccc|}
\hline Complications & GP A $(\mathrm{n}=35)$ & GP B $(\mathrm{n}=35)$ & P value \\
\hline No complication & $15(43)$ & $28(80)$ & 0.001 \\
Complication & $20(57)$ & $7(20)$ & \\
APH & $5(14.2)$ & $2(5.7)$ & 0.482 \\
Preeclapsia & $4(11.4)$ & $2(5.7)$ & \\
\hline
\end{tabular}




\begin{tabular}{|lclc|}
\hline Malpresention & $4(11.4)$ & $2(5.7)$ & 0.673 \\
Obstructed labour & $3(8.5)$ & 0 & 0.239 \\
Ruptured uterus & $1(2.8)$ & 0 & 0.999 \\
Impending rupture & $1(2.8)$ & 0 & 0.999 \\
Oligohydramnios & $2(5.7)$ & $1(2.8)$ & 0.999 \\
\hline
\end{tabular}

Pregnancy related complications were found significantly high in A group compared to B group.

Table-2 Mode of delivery

\begin{tabular}{|lccc|}
\hline Mode of devery & Group A(n=35) & Group B(n=35) & P-value \\
\hline NVD & $4(11.5)$ & $10(36.0)$ & 0.043 \\
LSCS & $31(88.5)$ & $25(63.0)$ & \\
& & & \\
\hline
\end{tabular}

Caesarian section was significantly higher in group A than group B.

Table-3: Indication of caesarean section among the case and control

\begin{tabular}{|lcc|}
\hline Complications & Group A $(\mathrm{n}=35)$ & Group B $(\mathrm{n}=35)$ \\
\hline Obstructed labour & $2(5.7)$ & $0(0.0)$ \\
Malpresention & $2(5.7)$ & $1(2.8)$ \\
Previous caesarian section & $2(5.7)$ & $1(2.8)$ \\
Fetal distress & $8(23.0)$ & $4(11.0)$ \\
Preeclampsia & $4(11.0)$ & $2(5.7)$ \\
Chaphalopelvic disproportion & $8(8.5)$ & $2(5.7)$ \\
& $2(5.7)$ & $1(2.8)$ \\
\hline
\end{tabular}

Majority of older patients needed caesarian section for previous caesarian section, obstructed labour, placenta previa \& fetal distress.

Table-4: Post delivery maternal complications

\begin{tabular}{|c|c|c|c|}
\hline Complications & $\begin{array}{c}\text { GP A }(n=35) \\
\text { No }(\%)\end{array}$ & $\begin{array}{c}\text { GP B }(n=35) \\
\text { No }(\%)\end{array}$ & $\mathrm{P}$ value \\
\hline No complication & $21(60)$ & $22(77)$ & 0.122 \\
\hline Complication & $14(40)$ & $8(23)$ & \\
\hline $\mathrm{PPH}$ & $3(8.5)$ & $2(5.8)$ & 0.999 \\
\hline Failure or & & & \\
\hline Inadequate & & & \\
\hline Lactation & $4(11.4)$ & $2(5.7)$ & 0.673 \\
\hline Wound infection & $2(5.8)$ & $1(2.8)$ & 0.999 \\
\hline Puerperal sepsis & $1(7)$ & 0 & 0.999 \\
\hline Post spinal headache & $2(5.8)$ & $2(5.7)$ & 0.999 \\
\hline
\end{tabular}


Feto-Maternal Out-Come Of Advanced Maternal Age-A Clinical Study In Bsmmu

\begin{tabular}{|lll|}
\hline Emergency & & \\
Peripartum hysterectomy 2(5.8) & $1(2.8)$ & 0.999 \\
\hline
\end{tabular}

Complications were more in A group compared to B group. But this finding has not seems to be significant.

Table 5: Perinatal mortality in relation to maternal age

\begin{tabular}{|lccc|}
\hline Condition & Group A (n=30) & Group B (n=33) & P value \\
\hline Alive & $30(86.0)$ & $33(94.4)$ & 0.478 \\
Still born & $3(8.5)$ & $1(2.8)$ & \\
Early neonata death & $2(5.7)$ & $1(2.8)$ & \\
\hline
\end{tabular}

There is no significant difference in condition of baby at birth between two groups.

During this study period total 1130 patients were admitted in BSMMU. Among them 65 patients were 35 years or above. Thirty five patients were selected consecutively for this study. From this admitted patient consecutive 35 patients were selected for this study, whose ages were above 35 years. At the same time 35 patients were selected as a control, whose age was below 35 years. Pregnancy complications were found significantly high in A group (57\%) compared to B group(20\%). Most common complications observed in group A were APH 14.2\%, preeclampsia 11.4\%, malpresentation $11.4 \%$, obstructed labour $8.5 \%$ oigohydramnions 5.7\%. Caesarian section was significantly high in both Group A(88.5\%) \& Group(63\%), followed by vaginal delivery(11.5\% Vs 37\%). Most common indication for caesarian sections for group A \& B was previous caesarian section $(23 \% \& 11 \%)$. Others indications for caesarian sections were chaphalopelvic disproportion(group-A8.5\% \& group-B2.8\%), fetal distress(groupA-11\%\&groupB5.7\%),APH(groupA5.7\% \&groupB-2.8\%),preeclapsia(both group A\&B was 5.7\%),malpresentation(group-A 5.7\% \& group-B $2.8 \%)$. Post delivery maternal complications were more in A group (40\%) compared to B group (23\%). PPH in A \& B group was respectively $8.5 \% \& 5.8 \%$, failure of lactation $11.5 \%$ \& 5.7\%, wound infection $5.8 \%$ \& $2.8 \%$, post spinal headache in both group was $5.7 \%$ \& emergency peripartum hysterectomy was $5.7 \%$ \& $2.8 \%$. Still born rate in Group A and Group B was respectively $8.5 \%$ \& $2.8 \%$, early neonatal death in group A \& B was respectively $5.7 \%$ \& $2.8 \%$.

\section{Discussion:}

In this study complications during pregnancy were more commonly found in elderly age group. Study found that woman in their 40s nearly three times as likely, as younger woman to have this complication. ${ }^{7}$ The most common complication was placenta previa. According to $\mathrm{M}$ jolly, increasing maternal age is associated independently with the risk of placenta previa $^{8}$.

The incidence of obstructed labour was seen higher in the elderly age (8.5\%) group in comparison of younger group (0\%). This study is consistent with the study of Khan $\mathrm{R}(2000)$ conducted in Dhaka Medical college Hospita ${ }^{9}$.Khan NT showed that obstructed labour was about $26 \%$ in comparism to younger group (13\%).9 The incidence of malpresention was found more commonly in elderly group $(11.4 \%)$ than younger group $(5.7 \%)$. This study was similar with the previous study ${ }^{10}$.

In the present study preterm delivery occurred more in the group A $(26 \%)$ than in the B group (17\%). Other study showed result consistent with present study ${ }^{10}$. This study is consistent with the study of KhanNT(2000) where it was found 14\% in the elderly group \& $8 \%$ in the younger age group. This is in contrast to the study done in Mount snail hospital in New York city, which showed that the rate of preterm delivery was not appreciably higher among elderly group. ${ }^{11}$

The incidence of normal vaginal delivery is less (11.5\%) among older group than younger group (37\%).

The rate of caesarian section is higher in older age group than that in control group $(88.5 \% \mathrm{Vs} 63 \%)$ which is statistically significant. The higher rate of caesarian section mainly due to repeat caesarian section and due to other complications like maternal medical disorder, obstructed labour, fetal distress etc. this study is comparable to the study done by Spellacy WN where higher incidence of caessarian section was found in older age group ${ }^{12}$. Studies in Gready Memorial Hospital revealed a nearly similar result ${ }^{13}$. Post delivery maternal complications were more in group A compared to B group (40\% Vs 23\%). The incidence of emergency peripartum hysterectomy was higher in group A than group B. this may be due to high parity seen in older age group. In this study in elderly group still birth rate was $8.5 \%$ and early neonatal death was $5.7 \%$ where as among group B still born rate was $2.8 \%$ and early neonatal death was $2.8 \%$. This study is consistent the study of Morrison, who particularly stressed the threefold increase in perinatal morbidity observed in older age group ${ }^{14}$. A number of studies have found that woman over age 40 are about twice as likely as woman in their 20 s to have a stillborn 
baby $^{15,16}$. Biological explanation for the higher rate of late fetal death in older woman includes reduced fetal oxygenation with maternal age, a rise in the frequency of preexisting hypertension with age and reduced uterine blood flow to the placenta.

There is no maternal mortality in this study. This was similar with that of Khan NT (2000). It was also similar with the findings of Spellacy WN10 Waters and Wanger ${ }^{17}$ found a maternal mortality of $1.2 \%$ in elderly woman. This study may be due to different sample size, different study places and variable monitoring facilities.

\section{Conclusion}

By this study we found that maternal complications were more during pregnancy in advanced maternal age. The incidence of pregnancy complications like obstructed labour, malpresention, APH, preclapsia and caesarean section were more commonly seen in pregnancy of advance age. But there is no significant difference in perinatal mortality and morbidity in advance maternal age compared to younger age.

\section{Reference:}

[1]. WWW.medterms.com/script/main/criticlekey=33289-35k date: 13 November, 2008

[2]. Hamisu M. Salihu, M. Nicole Shupert, MPH, Martha Slay, MPH, Russelle S Kirby and Alexander, ScD, Childbearring Beyond Maternal age 50 and fetal outcomes in the United states, Journal of Obstetrics and Gynaecology Original Research, November 2003, 102 number 5, part 1, pages 1006-1014.

[3]. Schwk K Mary, RNC, WHNP and direction of the womans well outreach program at SSm st Marry s health center in Richmond Geights2003.

[4]. Khan NT, Outcome of pregnancy in woman 35 years or above, FCPS part 2 (obs-gynae), Dissertation BSMMU, 2000.

[5]. Cleary-Goldman, J, et al. Impact of maternal age on Obstetric outcome. Obstetrics and Gynecology, volume 105, number 5, May 2005, pages 983-99.

[6]. GS Berkowitz, ML Skovron, RH Lapinski, Berkwitz, Delayed child bearing and the outcome of pregnancy. The new England journal of Medicine, 1990, No.10, volume 322, page 659-664.

[7]. Khan NT, Outcome of pregnancy in woman 35 years or above, FCPS part 2( Obs \& Gynae), Dissertation BSMMU,2000.

[8]. GJ Bugg, GS Atwal, M Maresh, Grand multipara in a modern setting, international Journal of Obstetrics and Gynaecology 2002, vol 109, page 249-253.

[9]. GS Berkowitz, ML Skvron, RH Lapinski, Berkwitz, Delayed childbearing and the outcome of pregnancy. The new England journal of medicine, 1990, No.10, Vol 322, page 659-664.

[10]. WN Spellacy, Sj Miller, A Wineger, Pregnancy after 40 years of age. Obstetric and Gynaecology, 1986; Vol 68, page 452-454

[11]. Grimes DA, Gross GK. Pregnancy outcome in black woman aged 35 and olde. Obstet. Gynaecol 1981; 58:614-20.

[12]. Philpott RH. Obstructed labour. IN: Philpott RH (ed). Clinics in Obstetric and Gynaecology London: W.B. sounders, 1982; 625-40.

[13]. joseph KS, et al. the pwrinatal effect of delayed childbearing American Journal of Obstetrics and Gynecology, vol 105, no R 6, June 2005, pages 1410-1418.

[14]. American college of Obstetrician and Gynecologists(ACOG). Later childbearing. ACOG, Washington DC, 1999, accessed $11 / 04 / 05$.

[15]. Rao KB, Perinatal mortality. In Ratnam ss, Rao KB, Arulkumaran S. Aditors, , Obstetrics and Gynaecology for postgraduates, volume- $2,1^{\text {st }}$ edition $(252-12)$. 